\title{
O controle judicial das omissões públicas como garantia de fruição dos direitos sociais pelos cidadãos
}

José dos Santos Carvalho Filho'

\section{Resumo}

Os direitos sociais, como direitos de segunda dimensão, exigem prestação positiva do Estado. O objetivo deste trabalho é analisar a função do Poder Judiciário na concretização desses direitos, controlando as omissões inconstitucionais dos outros Poderes Públicos.

Palavras-chave: Controle judicial. Omissões inconstitucionais. Direitos sociais. Eficácia.

\section{Apresentação do tema}

O Estado tal como é conhecido hoje, Estado Nacional ou Moderno, composto por território, poder político e população, nasceu absolutista. A vontade do rei era lei e as regras jurídicas eram definidoras do poder exíguas, vagas e não reduzidas a escrito. Subdivide-se em dois períodos: direito divino e Estado de Polícia, que busca atribuir ao poder uma fundamentação racionalista. Em um segundo momento, influenciado pelas ideias do constitucionalismo, tornou-se Estado Representativo ou de Direito. Limitado pelas liberdades individuais, pela divisão do Poderes e pela redução ao mínimo de suas funções recuou na participação nas relações privadas.

Continuando seu processo de evolução, o Estado passou a hipervalorizar a democracia, a qual não mais era exercida apenas por meio da participação indireta, mas também pela atuação cada vez mais constante do povo nas decisões políticas

\footnotetext{
${ }^{1}$ Bacharel em Direito pelo Instituto Camillo Filho. Servidor Público do Supremo Tribunal Federal. Professor de Direito Constitucional do Centro Educacional Fortium. Mestrando em Direito na área de concentração Constituição e Sociedade no Instituto Brasiliense de Direito Público - IDP. Email: jdscf_direito@yahoo.com.br
} 
de seu país. Acresceram-se os direitos políticos dos cidadãos ao rol dos direitos fundamentais.

Com o passar dos anos, todavia, percebeu-se que o absenteísmo total do Estado não é o ideal, tendo em vista a necessidade de interferências estatais com o escopo de reduzir as desigualdades sociais. Assim, surgiu o Estado Social, o denominado Estado Providência.

Posteriormente, valores de solidariedade social e responsabilidade comum foram ganhando crescente espaço na sociedade civil.

Impende esclarecer que todo o exposto é uma breve introdução que se faz necessária para o melhor entendimento do contexto em que surgiram os direitos sociais, bem como da evolução dos direitos fundamentais, a qual passou por três dimensões coincidentes com os estágios de modificação estatal: absolutista para liberal, liberal para social e social para pós-social, consoante é explanado a seguir.

A doutrina classifica os direitos fundamentais como: primeira, segunda e terceira dimensões. Os primeiros são os individuais e políticos clássicos; os últimos são os direitos de solidariedade ou de fraternidade, que englobam os direitos a uma saudável qualidade de vida, ao progresso, à paz, a um meio ambiente equilibrado e a outros direitos difusos; os segundos, por fim, são os direitos econômicos, culturais e sociais, para os quais será dispensada maior atenção.

O estabelecimento de constituições escritas está diretamente ligado à edição de declarações de direitos do homem, uma vez que são as constituições que citam o rol dos direitos fundamentais a serem assegurados pelo Estado.

Inicialmente, surgiram os direitos de primeira dimensão, que exigem prestação negativa do Estado, um deixar de agir, funcionando como verdadeiras escusas aos tentáculos estatais. Com o passar dos tempos, surgiram os direitos de segunda dimensão que, em contraposição aos seus antecessores, imprescindiram de conduta ativa do Estado, transformando-o em Estado Assistencial, cuja função é tentar propiciar a igualdade material dos cidadãos em detrimento da mera isonomia formal.

A Constituição da República Federativa do Brasil dispõe, em seu artigo sexto, que "são direitos sociais a educação, a saúde, o trabalho, a moradia, o lazer, a 
segurança, a previdência social, a proteção à maternidade e à infância, a assistência aos desamparados, na forma desta Constituição". Todos são direitos de segunda dimensão e dependem de atuação estatal para serem respeitados. Ocorre que nem sempre o Poder Público executa os programas que lhe são impostos pela Constituição, seja por ações ineficientes, seja por inércia.

No Brasil, vige o princípio da Separação dos Poderes coexistindo harmonicamente, o Legislativo, o Executivo e o Judiciário. O primeiro atua na elaboração de normas regulamentadoras,;o segundo, na administração de políticas públicas; e o último atua subsidiariamente, agindo quando há insuficiência de um dos outros Poderes no exercício de suas atribuições, para solucionar conflitos de interesses.

Como a função do Poder Legislativo é elaborar normas, se ele não as fizer, impedindo, assim, que um direito, liberdade ou prerrogativa constitucional dependente de regulamentação sejam exercidos, o Poder Judiciário entrará em cena fazendo o controle de constitucionalidade, mais especificamente, agirá para sanar a inconstitucionalidade por omissão, julgando ações diretas de inconstitucionalidade por omissão e mandados de injunção. Se elabora a norma, mas o faz de forma incompatível com as disposições constitucionais, o Judiciário atuará como legislador negativo, após provocação, por meio dos chamados processos objetivos, declarando a inconstitucionalidade da lei.

Não obstante existirem os meios de controle concentrados de constitucionalidade, que têm validade erga omnes, o Judiciário pode ainda ser provocado para agir dentro de um processo subjetivo, incidentalmente, situação em que fará o controle difuso de constitucionalidade, com validade inter partes.

O controle da atuação do Poder Executivo, por sua vez, é bem mais complicado.

Como dito supra, os direitos de segunda dimensão, nos quais estão inseridos os direitos sociais, exigem prestação positiva do Estado, um facere, a realização de políticas públicas que assegurem os direitos, liberdades e prerrogativas previstos na Constituição, a constar: saúde, moradia, educação e trabalho, dentre outros.

A efetivação de tais políticas, no entanto, está condicionada à existência de verbas disponíveis para sua realização; aqui reside o principal limite para a atuação da Administração Pública. 
Citar direitos sociais e dizer que o Poder Público tem a função de garanti-los, a Constituição fez muito bem, porém permaneceu desatenta à realidade sócio-política brasileira, que não tem condições fáticas para assegurar a grande quantidade de direitos nela previstos.

Sobre o tema, Manoel Gonçalves Ferreira Filho leciona de forma precisa:

A Constituição de 1988 agravou a governabilidade brasileira ao sobrecarregar o Estado de tarefas, sem providenciar os recursos para as mesmas, ou seja, preocupou-se com a distribuição das riquezas, não com a produção delas ${ }^{2}$.

Assim, ou o Poder Público paga uma quantia possível como salário mínimo aos seus servidores, ou leva o país à falência, pagando mais do que pode, para garantir salário capaz de atender ao trabalhador e à sua família com moradia, alimentação, educação, saúde, vestuário, higiene, transporte, previdência social, além de ter que fazer reajustes periódicos para manter o seu poder aquisitivo (CF, art. $\left.7^{\circ}, \mathrm{IV}\right)$. A questão parece ser simples, o Estado não faz o que ele não pode.

Todavia, em não cumprindo as ordens constitucionais, que expressamente estabelecem o dever do Estado de garantir salário-mínimo nessas condições, por exemplo, o Estado está esvaziando o conteúdo da Constituição.

Nesse contexto, surgem três teorias que são assaz importantes. A primeira delas é a teoria das normas programáticas, a qual preceitua que as normas que estabelecem os direitos sociais têm caráter programático, não sendo esses direitos exigíveis do Estado de imediato.

Sobre o assunto, José Afonso da Silva afirma que:

O problema que se coloca agudamente na doutrina recente consiste em buscar mecanismos constitucionais e fundamentos teóricos para superar o caráter abstrato e incompleto das normas definidoras de direitos sociais, ainda concebidas como programáticas, a fim de possibilitar sua concretização prática ${ }^{3}$.

\footnotetext{
${ }^{2}$ FERREIRA FILHO, Manoel Gonçalves. Constituição e governabilidade: ensaio sobre a (in) governabilidade brasileira. São Paulo: Saraiva, 1995.

${ }^{3}$ SILVA, José Afonso da. Aplicabilidade das normas constitucionais. 7. ed. São Paulo: Malheiros, 2007.
} 
Ocorre que as normas constitucionais são dotadas de imperatividade e não podem ser interpretadas como promessa constitucional inconsequente, sob pena de o Poder Público frustrar as expectativas da sociedade e descumprir o seu impostergável dever institucional, por um gesto irresponsável de infidelidade governamental ao que determina o Texto Constitucional. ${ }^{4}$

As normas constitucionais, que são preceptivas, não podem simplesmente perder sua imperatividade por orientação jurisprudencial. Esse entendimento é assente na doutrina:

Vemos com frequência os publicistas invocarem tais disposições para configurar a natureza política e ideológica do regime, o que, aliás, é correto, enquanto a invocação não abrigar uma segunda intenção, por vezes reiterada, de legitimar a inobservância de algumas determinações constitucionais. Tal acontece com denunciações diretivas formuladas em termos genéricos e abstratos, às quais comodamente se atribui a escusa evasiva da programaticidade como expediente fácil para justificar o descumprimento da vontade constitucional. ${ }^{5}$

A segunda teoria reserva do possível, justifica a omissão do Poder Público com a escassez de recursos. Considerando as limitações de ordem econômica à efetivação dos direitos sociais, sustenta-se que estes estariam condicionados ao que se passou a chamar de reserva do possível, conceito oriundo da Alemanha, baseada em decisão da Corte Constitucional Federal, a qual firmou o posicionamento de que o indivíduo só pode requerer do Estado uma prestação que se dê nos limites do razoável ${ }^{6}$.

Nas palavras de Rosalia Carolina Kappel Rocha:

A efetividade, a aplicabilidade e a concretização especialmente dos direitos sociais exigem conduta estatal. Entretanto, na concretização desses direitos, não há como escapar da

\footnotetext{
${ }^{4}$ BRASIL. Supremo Tribunal Federal. Agravo regimental em recurso extraordinário $n^{\circ}$ 393175. Relator: Ilmar Galvão. 12 dezembro 2006. Disponível em: <www.stf.gov.br>. Acesso em: 04 set. 2008.

${ }^{5}$ BONAVIDES, Paulo. Curso de direito constitucional. 20. ed. São Paulo: Malheiros, 2007.

${ }^{6}$ LIMA, Flávia Danielle Santiago. Em busca da efetividade dos direitos sociais prestacionais. Considerações acerca do conceito de reserva do possível e do mínimo necessário. Jus $\mathrm{Na}$ vigandi, Teresina, ano 5, n. 51, out. 2001. Disponível em: <http://jus2.uol.com.br/doutrina/ texto.asp?id=2177>. Acesso em: 11 set. 2008.
} 
sua adequação e harmonização à realidade e à possibilidade fática da própria atividade prestacional.

$[\ldots]$

Vê-se, pois, que a questão não é tão simples, não bastando a mera positivação no ordenamento jurídico para tornar determinado direito realmente efetivo, já que a situação concreta é que vai indicar a possibilidade da realização da pretensão buscada. Não há como desconsiderar ainda que, enquanto as necessidades públicas são infinitas ou tendentes ao infinito, os recursos são finitos. Necessária, pois, a visão conjuntural, não apenas frente a demais direitos e valores sociais que eventualmente possam estar envolvidos, mas também as condições materiais e econômicas necessárias para a concretização do direito ${ }^{7}$.

Mas as teorias das normas programáticas e da reserva do possível não podem coibir o exercício de direitos mínimos, logo elas só parecem ter sentido, quando conjugadas com a teoria do mínimo existencial. Por essa teoria, independentemente dos recursos disponíveis, o Estado deve garantir o mínimo necessário para que a pessoa tenha uma existência digna.

Segundo Andreas Krell, a proteção a um mínimo social não pode ser condicionada à aplicação da reserva do possível, isto é, a proteção do direito à saúde não pode ficar à mercê dos orçamentos públicos ${ }^{8}$.

É com fulcro nessa teoria que, não raramente, alguns necessitados têm conseguido internações hospitalares ou concessão de remédios via impetração de mandado de segurança, por exemplo. O direito à saúde ainda não pode ser garantido em sua plenitude, mas há um mínimo que deve ser preservado, a fim de resguardar o bem mais valioso do homem, a vida.

Nesse sentido, transcreve-se a decisão infra, oriunda do Tribunal Regional Federal da Quarta Região:

ADMINISTRATIVO. CONSTITUCIONAL. DIREITOS FUNDAMENTAIS. DIREITO À SAÚDE. ARTS. 6 E 196 DA

\footnotetext{
${ }^{7}$ ROCHA, Rosalia Carolina Kappel. A eficácia dos direitos sociais e a reserva do possível Disponível em: <http://www.escola.agu.gov.br/revista/Ano_V_novembro_2005/rosaliaeficacia.pdf $>$. Acesso em: 01 set.2008.

${ }^{8}$ KRELL, Andreas. Direitos sociais e controle judicial no Brasil e na Alemanha: os (des)caminhos de um direito constitucional "comparado". Porto Alegre: Sérgio Fabris, 2002..
} 
CF/88. EFICÁCIA IMEDIATA. MÍNIMO EXISTENCIAL. RESERVA DO POSSÍVEL. INAPLICABILIDADE.

1. Mesmo que situado, como comando expresso, fora do catálogo do art. $5^{\circ}$ da CF/88, o direito à saúde ostenta o rótulo de direito fundamental, seja pela disposição do art. $5^{\circ}, \$ 2^{\circ}$, da $\mathrm{CF} / 88$, seja pelo seu conteúdo material, que o insere no sistema axiológico fundamental - valores básicos - de todo o ordenamento jurídico.

2. Os direitos fundamentais, consoante a moderna diretriz da interpretação constitucional, são gravados pela eficácia imediata. A Lei Maior, no que diz com os direitos fundamentais, deixa de ser mero repositório de promessas, carta de intenções ou recomendações; houve a conferência de direitos subjetivos ao cidadão e à coletividade, que se vêem amparados juridicamente a obter a sua efetividade, a realização em concreto da prescrição constitucional.

3. Consoante os novos rumos interpretativos, a par de darse eficácia imediata aos direitos fundamentais, atribuiuse ao intérprete a missão de desvendar o grau de eficácia imediata dos direitos fundamentais, porquanto, mesmo que se pretenda dar máxima elasticidade à premissa, nem sempre se estará infenso a uma interpositio legislatoris, o que não ocorre, vale afirmar, na porção do direito que trata do mínimo existencial.

4. A escassez de recursos públicos, em oposição à gama de responsabilidades estatais a serem atendidas, tem servido de justificativa à ausência de concretização do deverser normativo, fomentando a edificação do conceito da "reserva do possível". Porém, tal escudo não imuniza o administrador de adimplir promessas que tais, vinculadas aos direitos fundamentais prestacionais, quanto mais considerando a notória destinação de preciosos recursos públicos para áreas que, embora também inseridas na zona de ação pública, são menos prioritárias e de relevância muito inferior aos valores básicos da sociedade, representados pelos direitos fundamentais.

5. A moderna doutrina, bem como autorizada jurisprudência, retirou força do dogma da intangibilidade do mérito administrativo, deixando ao Judiciário a faculdade de examinar também a motivação, sob o aspecto 
da razoabilidade, tomando considerável espaço onde imperava a discricionariedade. [...] (Grifo nosso). ${ }^{9}$

Ao lume de todo o exposto, percebe-se que os dispositivos constitucionais não podem se tornar letra morta. A Constituição é suprema, supralegal e tem força normativa. Portanto, seus preceitos devem ser cumpridos, ainda que o Judiciário tenha que intervir para tanto.

Não se trata de interferência de um Poder no outro, mas no cumprimento de funções institucionais. Se a Constituição preceitua que um direito, liberdade ou prerrogativa devem ser garantidos pelos Poderes Públicos e estes descumprem as ordens constitucionais, cabe ao Judiciário exercer seu papel de fazer cumprir os preceitos da Lei Maior, mormente ao Supremo Tribunal Federal, por ser guardião máximo da Constituição.

É bastante oportuna a lição de Lênio Luiz Streck, segundo o qual:

O problema eficacial do texto constitucional passa, fundamentalmente, pelo tipo de justiça constitucional praticado em cada país e pelo redimensionamento do papel dos operadores do Direito. Para tanto, deve ficar claro que a função do Direito - no modelo instituído pelo Estado Democrático de Direito - não é mais aquela do Estado Liberal-Absenteísta. O Estado Democrático de Direito representa um plus normativo em relação ao Estado Liberal e até mesmo ao Estado Social. A Constituição brasileira, como a de Portugal, Espanha e Alemanha, por exemplo, em que pese o seu caráter aberto, é uma Constituição densa de valores, compromissária e voltada para a transformação das estruturas econômicas e sociais. Dito de outro modo, além da carga elevada de valores e do caráter compromissário do texto da Constituição brasileira, este traz em seu bojo os mecanismos para a implantação dos direitos sociais e fundamentais, compatíveis com o atendimento ao princípio da dignidade da pessoa humana. A tarefa de aplicá-los é dos juristas ${ }^{10}$

\footnotetext{
${ }^{9}$ BRASIL. Tribunal Regional Federal (4. Região). Embargos infringentes na apelação cível processo $n^{\circ} 199904010149449-R S$. Órgão Julgador: segunda seção. Data da decisão: 08 nov. 2004. Disponível em: <www.trf4.gov.br> Acesso em: 20 jan. 2008.

${ }^{10}$ STRECK, Lênio Luiz. Os meios e acesso do cidadão à jurisdição constitucional, a arguição de descumprimento de preceito fundamental e a crise de efetividade da Constituição Brasileira. In: HERMENÊUTICA e jurisdição constitucional. Belo Horizonte: Del Rey, 2001.
} 
Destarte, percebe-se que o Poder Judiciário, ao condenar o Executivo na concretização de direitos constitucionais que estão sendo tolhidos, não faz nada além de executar sua função típica de velar pelo cumprimento das leis, mormente da Constituição.

Essa postura parece não agradar o governo. Recentemente, o Presidente da República asseverou que seria muito bom se o Poder Judiciário só "metesse o nariz" nos seus próprios assuntos.

Mas o Presidente parece esquecer que a função típica do Judiciário é justamente agir como terceiro imparcial, para solucionar conflitos de interesses de outras pessoas. O interesse alheio é que propicia meios para garantir a imparcialidade judicial.

Invoca-se a manifestação de Ellen Gracie, do Supremo Tribunal Federal, sobre o assunto:

O Judiciário é um Poder inerte. Ele só age quando provocado pelas vias legais. Quando recebemos uma ação, contudo, temos de dar resposta - e isso às vezes significa estabelecer uma regra, ou ampliar o escopo de uma lei que já existe. Foi o que fizemos recentemente, por exemplo, ao aplicar às greves do serviço público as normas que valem no setor privado. Ou ao afirmar que o mandato de um parlamentar pertence ao seu partido. Seria mais confortável para nós não ter de lidar com esse tipo de dificuldade. Mas, às vezes, as questões se arrastam por anos no Congresso e acabam desaguando no Judiciário ${ }^{11}$.

Percebe-se, pois, que não é fácil ao Judiciário tomar posicionamentos polêmicos, mas ele tem de fazer, sob pena ,mantida a inércia dos outros Poderes, os direitos, as liberdades e as prerrogativas constitucionalmente previstos, ficarem apenas no plano da abstração.

O que se defende, entretanto, não é um ativismo judicial exacerbado, mas tão-só a legitimidade que o Judiciário tem para controlar as políticas públicas, que têm sido negadas, a pretexto de separação dos poderes. Por ser um Poder técnico, ao contrário do Legislativo e do Executivo, o Judiciário não detém conhecimento suficiente para estipular políticas públicas, além de não ter essa função institucional.

11 NORTHFLEET, Ellen Gracie. Fé na justiça. Veja, São Paulo, n. 19, p. 11-15, maio 2009. 
Mas há casos que a própria Constituição já estipula as políticas a serem concretizadas pelo Estado e essa é uma das situações em que o Judiciário pode atuar. Se o Executivo não repassa o valor que a Lei Fundamental impõe que seja empregado na educação, por exemplo, o Judiciário pode obrigá-lo a efetuar o repasse.

Ana Paula de Barcellos cita mais dois casos objetivos em que a atuação judicial é legítima, quais sejam: persecução das metas prioritárias do Estado e verificação de um grau mínimo de eficiência das políticas públicas selecionadas.

Pelo último critério, o Judiciário tem o poder de analisar se a política pública eleita pelo Executivo atende ao mínimo de eficiência para caminhar rumo à concretização dos direitos sociais, enquanto o primeiro requer que sejam propiciados os direitos mais básicos antes dos menos indispensáveis - a verba destinada à educação deve ser empregada inicialmente no ensino fundamental e, em caso de remanescência, no ensino médio ${ }^{12}$.

Sobre o controle judicial de políticas públicas, o direito à saúde é o mais polêmico. $\mathrm{O}$ ativismo do Judiciário cresceu tanto que já se cogita uma crise de governabilidade. Ao condenar o Executivo a realizar determinada política pública, o Judiciário compromete parte do orçamento público.

É curioso quando se trata de ações individuais, pois as verbas públicas que seriam destinadas a programas coletivos são desviadas para uma só pessoa. Nesse contexto, percebe-se um conflito entre o direito à vida ou à saúde de uma pessoa e o direito à vida ou à saúde da coletividade ${ }^{13}$. Nesse caso, é o direito coletivo que deve prevalecer ante o postulado da supremacia do interesse público sobre o privado.

Quando o Executivo é condenado a custear tratamentos de saúde caríssimos em benefício de uma única pessoa, o Estado deixa de investir esse dinheiro em programas preventivos de saúde, que, em longo prazo, são mais eficientes para toda a coletividade.

\footnotetext{
${ }^{12}$ BARCELLOS, Ana Paula de. Neoconstitucionalismo, direitos fundamentais e políticas públicas. Revista de Direito Administrativo, Rio de Janeiro, n. 240, p. 83-103. abr./ jun. 2005.

${ }^{13}$ BARROSO, Luís Roberto. Da falta de efetividade à judicialização excessiva: direito à saúde, fornecimento gratuito de medicamentos e parâmetros para a atuação judicial. In: SOUZA NETO, Cláudio Pereira de; SARMENTO, Daniel (Coord.). Direitos sociais: fundamentos, judicialização e direitos sociais em espécie. Rio de Janeiro: Lumen Júris, 2008.
} 
Não parecem corretas, portanto, algumas decisões judiciais que condenam o Estado a fornecer medicamentos importados e que ainda estão em fase experimental, sem se falar na responsabilidade solidária que o Judiciário insiste em impor aos entes políticos.

Ocorre que os entes políticos elaboram esquemas de atuação e partilham atribuições, sendo cada um responsável pelo fornecimento de determinados medicamentos. Quando um hipossuficiente tenta, sem sucesso, conseguir um remédio, ele recorre ao Judiciário, que não analisa quem é o responsável pelo fornecimento do remédio e condena todos os entes federados solidariamente.

Essa postura mais parece ser melhor do que efetivamente é, pois compromete a atuação governamental e privilegia um indivíduo em detrimento da coletividade. O Judiciário tem que tutelar o direito à saúde, isso é óbvio, mas sua atuação deve priorizar a saúde da coletividade.

Feitas essas considerações, também não se sustenta que o Estado deixe os necessitados morrerem à míngua, mas a atuação não pode ser tão extremista, ou acabará gerando uma crise de governabilidade no país.

\section{Conclusão}

Ao lume de todo o exposto, pode-se concluir que em um país onde reina o individualismo, os cidadãos devem ter garantidos, pelo menos, seus direitos básicos. Se a preocupação com a coletividade fosse maior, talvez medidas judiciais não precisassem ser adotadas.

Enquanto os Poderes Executivo e Legislativo não cumprirem os comandos constitucionais de forma satisfatória, cabe ao Judiciário continuar intervindo, a fim de concretizar os direitos, liberdades e prerrogativas constitucionais que estão sendo tolhidos aos cidadãos.

As ações constitucionais são os meios adequados para sanar condutas inconstitucionais do Estado, e o Ministério Público também desempenha fundamental papel, sobretudo por ser instituição destinada à proteção dos interesses coletivos e difusos, e por possuir titularidade de várias ações como a ação civil pública. 
As normas constitucionais são preceptivas e seu conteúdo não pode ser esvaziado, nem mesmo por conduta de um dos Poderes constituídos, o qual é subordinado ao poder soberano constituinte do qual emana a Constituição.

Em síntese, dirigismo constitucional e reserva do possível, por si só, não são argumentos justificadores para o descumprimento dos comandos constitucionais destinados a dar concretude aos direitos sociais. Caso essas teorias sejam invocadas como escusas para a inércia, o Poder Judiciário pode ser acionado para refutálas e obrigar o Poder responsável pela omissão a agir.

Igualmente, se a normatividade infraconstitucional editada vai de encontro aos preceitos do Texto Maior, o Judiciário deve ser acionado; neste caso, para suprir o vício por meio do controle de constitucionalidade. Mas o controle judicial das políticas públicas também não pode ser exagerado, a ponto de condenar o Estado a custear tratamento de saúde no exterior, por exemplo.

A delimitação da legitimidade do controle jurisdicional ainda é imprecisa. Sabe-se que, para resguardar as políticas públicas expressamente previstas na Lei Maior, como as políticas de educação, o Judiciário deve, inequivocamente, agir, mas nos demais campos há muita celeuma, pois não se pode adotar uma insensível orientação absenteísta, mas também é incorreto um ativismo exacerbado. O equilíbrio é o ideal caminho para a solução desse problema.

\section{The Judicial control of State omissions as a garantee of ctiziens social rights fruition}

\section{Abstract}

Social rights, as second dimension rights, require positive provision from State. The objective of this work is analyzing the function of the Judiciary Power to implement these rights, controlling unconstitutional omissions from other Public Powers.

Keywords: Judicial control. Unconstitutional omissions. Social rights. Efficacy. 


\section{Referências}

BARCELLOS, Ana Paula de. Neoconstitucionalismo, direitos fundamentais e políticas públicas. Revista de Direito Administrativo, Rio de Janeiro, n. 240, p. 83-103. abr./ jun. 2005.

BARROSO, Luís Roberto. Da falta de efetividade à judicialização excessiva: direito à saúde, fornecimento gratuito de medicamentos e parâmetros para a atuação judicial. In: SOUZA NETO, Cláudio Pereira de; SARMENTO, Daniel (Coord.). Direitos sociais: fundamentos, judicialização e direitos sociais em espécie. Rio de Janeiro: Lumen Júris, ano. p. ??-??

BONAVIDES, Paulo. Curso de direito constitucional. 20. ed. São Paulo: Malheiros, 2007.

BRASIL, Constituição (1988). Constituição da República Federativa do Brasil. Brasília: Senado Federal, 2008.

BRASIL. Supremo Tribunal Federal. Agravo regimental em recurso extraordinário $n^{\circ}$ 393175. Relator: Ilmar Galvão. Data da decisão: 12 dez. 2006. Disponível em: <www.stf.gov.br>. Acesso em: 04 set. 2008.

BRASIL. Tribunal Regional Federal (4. Região). Embargos infringentes na apelação cível processo $n^{\circ}$ 199904010149449-RS. Órgão Julgador: segunda seção. Data da decisão: 08 nov. 2004. Disponível em: <www.trf4.gov.br> Acesso em: 20 jan. 2008.

FERREIRA FILHO, Manoel Gonçalves. Constituição e governabilidade: ensaio sobre a (in)governabilidade brasileira. São Paulo: Saraiva, 1995.

LIMA, Flávia Danielle Santiago. Em busca da efetividade dos direitos sociais prestacionais. Considerações acerca do conceito de reserva do possível e do mínimo necessário. Jus Navigandi, Teresina, ano 5, n. 51, out. 2001. Disponível em: <http://jus2.uol.com.br/doutrina/texto.asp?id=2177>. Acesso em: 11 set. 2008 .

KRELL, Andreas. Direitos sociais e controle judicial no Brasil e na Alemanha: os (des)caminhos de um direito constitucional "comparado". Porto Alegre: Sérgio Fabris, 2002.

NORTHFLEET, Ellen Gracie. Fé na justiça. Veja, São Paulo, n. 19, p. 11-15, maio 2009. 
ROCHA, Rosalia Carolina Kappel. A eficácia dos direitos sociais e a reserva do possível. Disponível em: <http://www.escola.agu.gov.br/revista/Ano_V_ novembro_2005/rosalia-eficacia.pdf>. Acesso em: 01 set.2008.

SILVA, José Afonso da. Aplicabilidade das normas constitucionais. 7. ed. São Paulo: Malheiros, 2007.

STRECK, Lênio Luiz. Os meios e acesso do cidadão à jurisdição constitucional, a arguição de descumprimento de preceito fundamental e a crise de efetividade da Constituição Brasileira. In: HERMENÊUTICA e jurisdição constitucional. Belo Horizonte: Del Rey, 2001. 